\title{
Feasibility of Reprocessing Natural Fiber Filled Poly(lactic acid) Composites: An In-Depth Investigation
}

\author{
Sujal Bhattacharjee and Dilpreet S. Bajwa \\ Department of Mechanical Engineering, North Dakota State University, Fargo, ND 58108-6050, USA \\ Correspondence should be addressed to Dilpreet S. Bajwa; dilpreet.bajwa@ndsu.edu
}

Received 30 March 2017; Revised 22 May 2017; Accepted 29 May 2017; Published 27 July 2017

Academic Editor: Luigi Nicolais

Copyright (C) 2017 Sujal Bhattacharjee and Dilpreet S. Bajwa. This is an open access article distributed under the Creative Commons Attribution License, which permits unrestricted use, distribution, and reproduction in any medium, provided the original work is properly cited.

\begin{abstract}
Poly(lactic acid) (PLA) based composites are biodegradable; their disposal after single use may be needless and uneconomical. Prodigal disposal of these composites could also create an environmental concern and additional demand for biobased feedstock. Under these circumstances, recycling could be an effective solution, since it will widen the composite service life and prevent the excessive use of natural resources. This research investigates an in-depth impact of recycling on the mechanical and thermomechanical properties of oak wood flour based PLA composites. Two composite formulations ( 30 and $50 \mathrm{wt} \%$ filler), each with $3 \mathrm{wt} \%$ coupling agent (PLA-g-MA), were produced and reprocessed six times by extrusion followed by injection molding. Measurements of fiber length and molecular weight of polymer were, respectively, carried out by gel permeation chromatography (GPC). Scanning electron microscopy (SEM), differential scanning calorimetry (DSC), thermogravimetric analysis (TGA), and Fourier transform infrared spectroscopy (FTIR) tools were used to study morphological and molecular alterations. With consecutive recycling, PLA composites showed a gradual decrease in strength and stiffness properties and an increase in strain properties. The $50 \%$ and $30 \%$ filler concentration of fibers in the composite showed an abrupt decrease in strength properties after six and two reprocessing cycles, respectively.
\end{abstract}

\section{Introduction}

Currently, biodegradable polymers and their natural fiber composites are preferred to nonbiodegradable plastics and their composites all over the world [1-3]. This is because biodegradable polymers and their natural fiber composites are not only environment friendly but also capable of higher physicomechanical properties. Nonbiodegradable polymers can create huge environmental pollution at the end of their life cycle (by disposal in landfills and incineration); in addition, the petroleum based polymers have limited reserves [47]. A widely popular biodegradable polymer polylactic acid (PLA) is an aliphatic thermoplastic polyester generated by polymerization or polycondensation of monomers of lactic acid and these monomers can be produced from natural resources such as sugar, beet, wheat, and corn $[7,8]$. PLA has higher strength and stiffness and is regarded as the best of all environment friendly polymers [5]. It has a wide range of application such as in biomedical field (e.g., drug delivery devices, sutures, and scaffolds), electronic field (e.g., portable device housings), automotive industry and construction (e.g., interior panels and indoor furnishing), and disposable items (e.g., packaging, plastic bags, disposable cups and plates, and compostable bottles) [4, 9-13]. However, incorporation of fiber in PLA is desired since the polymer itself is not able to meet all the anticipated properties and is relatively expensive [14]. Wood fiber is an attractive filler due to its cost, availability, biodegradability, and higher specific strength, and stiffness $[2,5,6,15]$. Therefore, incorporation of wood fiber/filler (WF) in PLA is a logical approach to create an economical and completely biodegradable composite.

Unfortunately, PLA and WF based composites have some minor drawbacks. Even though natural fiber reinforced composites have well established commercial market, PLA as matrix resin is yet to be extensively used in commercial engineering applications because of its lower impact resistance, lower softening temperature, higher brittleness, poor moisture resistance, and lower heat deflection temperature 
$[2,8,16-18]$. The manufacturing cost of PLA is comparatively higher, and the profitability of manufacturing has not yet been established strongly enough to be trusted [14]. Similarly, WF also has some shortcomings such as lower bulk density, higher heat sensitivity, and its hygroscopic nature [2]. Nonuniform dispersion of filler can result in less stress transfer from the matrix to fiber and can reduce the load carrying capacity of the composite [15]. Nevertheless, despite these challenges, the use of WF as filler in PLA is increasing globally primarily because of their biodegradability and higher specific properties [5].

With increased demand for WF-PLA composites what concerns is their premature disposal after single use. From a rational point of view, disposal of these WPCs after single use could produce a huge amount of waste material, which is unnecessary and uneconomic. Additionally, this extravagant disposal would create more demand for PLA resulting in greater demand for biobased feedstocks. To overcome this situation, reprocessing or recycling could serve as a competent alternative. Reprocessing would enhance the life cycle (service life) of composites and reduce the consumption of the renewable natural resources. As a result, it will have a positive impact on the environment and could improve the economics of PLA based composites.

Some research has been done to investigate the potential of reprocessing PLA based composites $[1,2,15]$. However, most of the research has focused on understanding the impact of blending recycled and virgin PLA polymers and its impact on physicomechanical properties. The studies found that mechanical properties of the composites initially remained constant and then started decreasing with increase in recycled content or number of reprocessing cycles. The degradation was mainly attributed to fiber length reduction and polymer degradation $[1,15,19]$.

The aim of this research is to understand the impact of reprocessing on the mechanical and thermomechanical properties of oak wood flour (WF) filled PLA composites. Two PLA based composite formulations with 30 or $50 \mathrm{wt} \%$ wood filler, $3 \mathrm{wt} \%$ coupling agent were selected and successively reprocessed six times by extrusion. After each extrusion cycle, test samples were prepared from composite pellets by injection molding.

\section{Materials and Methods}

2.1. Materials. Oak wood flour was obtained from Southern Wood Services, GA, USA. The particle size distribution of wood flour is shown in Table 1. The initial moisture content of wood flour was $5.5 \%$ as measured by using a moisture analyzer (Computrac, Model MAX 4000XL, AZ, USA). PLA (Ingeo Biopolymer 2003D) was obtained from NatureWorks LLC, MN, USA. The polymer has a MFI of $6 \mathrm{~g} / 10 \mathrm{~min}$ $\left(210^{\circ} \mathrm{C}, 2.16 \mathrm{Kg}\right)$, specific gravity of 1.24 , and heat deflection temperature of $55^{\circ} \mathrm{C}$. Coupling agent PLA grafted maleic anhydride (MA) was manufactured in the laboratory using MA and PLA through extrusion process. Maleic anhydride (2,5-furandione) with molecular weight 98.06 and purity greater than 99\% was purchased from Sigma Aldrich (St. Louis, MO, USA).
TABLE 1: Particle size distribution of oak wood flour.

\begin{tabular}{lc}
\hline Wood particle size $(\mathrm{mm})$ & Range $(\%)$ \\
\hline 0.841 & $0-5 \%$ \\
0.595 & $5-15 \%$ \\
0.400 & $35-42 \%$ \\
0.250 & $40-50 \%$ \\
0.177 & $6-9 \%$ \\
0.149 & $0-1 \%$ \\
$<0.149$ & $0-2 \%$ \\
\hline
\end{tabular}

\subsection{Methods}

2.2.1. Composite Preparation. Two PLA composite formulations with 30 and $50 \mathrm{wt} \%$ wood flour each and $3 \mathrm{wt} \%$ PLAg-MA were manufactured and then individually recycled six times by extrusion. Before extrusion, WF, PLA-g-MA, and PLA were dried in an oven at $80^{\circ} \mathrm{C}$ for 24 hours. The moisture content of dried wood flour and PLA before processing was below $0.5 \%$. The dried materials were manually blended and extruded into pellets using a twin screw corotating extruder (Leistritz Micro 18 GL 40 D, NJ, USA) with seven heating zones. The temperature profile of these zones (from feed section to melting section) was controlled at $157^{\circ} \mathrm{C}, 180^{\circ} \mathrm{C}$, $190^{\circ} \mathrm{C}, 200^{\circ} \mathrm{C}, 200^{\circ} \mathrm{C}, 202^{\circ} \mathrm{C}$, and $205^{\circ} \mathrm{C}$, respectively. Temperature of strand die and the gate adapter was maintained at $205^{\circ} \mathrm{C}$ and extruder screw speed at $200 \mathrm{rpm}$. Extruded composite strands were cooled down using a water bath and then pelletized. A portion of composite pellets were dried at $80^{\circ} \mathrm{C}$ and injection-molded using single-screw injection molder (Model SIM- 5080, Technoplas Inc., OH, USA) to make test samples of "cycle 0" or "virgin" composite material.

The rest of the dried virgin composite pellets were again extruded under the same processing conditions and injection-molded to make test samples of "cycle 1" or "first time recycled" composite. This process was repeated five times to derive test samples representing six reprocessing cycles. All the test samples were conditioned at room temperature $\left(25^{\circ} \mathrm{C}\right)$ before testing. The annotations for $30 \mathrm{wt} \%$ filler and $50 \mathrm{wt} \%$ filler composites are as "WF 30 PLA" and "WF 50 PLA" composites, respectively.

2.2.2. Tensile Testing. Tensile test was performed with a universal testing machine Instron (Model 5567, MA, USA) according to ASTM D 638: standard test method for tensile properties of plastics. A $30 \mathrm{KN}$ load cell and strain rate of $5 \mathrm{~mm} / \mathrm{min}$ were used in the test.

2.2.3. Flexural Testing. Flexural test was conducted using an universal testing machine (Instron Model 5567, MA, USA) with a load cell of $2 \mathrm{KN}$, according to ASTM D 790: standard test methods for flexural properties of unreinforced and reinforced plastics and electrical insulating materials. The crosshead speed was set at $1.4 \mathrm{~mm} / \mathrm{min}$. The sample dimensions were $75 \mathrm{~mm} \times 12.9 \mathrm{~mm} \times 3.3 \mathrm{~mm}$ with a support span of $53 \mathrm{~mm}$.

2.2.4. Coefficient of Thermal Expansion (CTE). The coefficient of thermal expansion was performed by using a 
dynamic mechanical analyzer (TA Instruments, DMA Q800, DE, USA) with the aid of a tension film clamp. The sample dimensions were $38.1 \mathrm{~mm} \times 12.9 \mathrm{~mm} \times 3.3 \mathrm{~mm}$ where the initial length was $12.74 \mathrm{~mm}$. Eight samples, for each cycle, were conditioned at room temperature and then tested from $30^{\circ} \mathrm{C}$ to $50^{\circ} \mathrm{C}$ with a ramp rate of $3^{\circ} \mathrm{C} / \mathrm{min}$. CTE was measured by using the following equation [22]:

$$
\alpha=\left(\frac{\Delta L}{\Delta T}\right) \cdot\left(\frac{1}{L}\right) .
$$

Here, $\alpha$ is the coefficient of thermal expansion, $\Delta L$ is the change in length, $\Delta T$ is the change in temperature, and $L$ is the initial length $(12.74 \mathrm{~mm})$.

2.2.5. Heat Deflection Temperature (HDT). Heat deflection temperature was determined by using a dynamic mechanical analyzer (TA Instruments, DMA Q800, DE, USA) according to ASTM D 648: standard test method for deflection temperature of plastics under flexural load in the edgewise position (pressure $\delta=0.455 \mathrm{MPa}$ ). Sample dimensions were $65.0 \mathrm{~mm}$ $\times 12.9 \mathrm{~mm} \times 3.3 \mathrm{~mm}$ and the supported length was $50 \mathrm{~mm}$. The temperature ramp rate was $3^{\circ} \mathrm{C} / \mathrm{min}$.

2.2.6. Dynamic Mechanical Analysis. Storage modulus was determined by using the dynamic mechanical analyzer (TA Instruments, DMA Q800, DE, USA) with a dual cantilever beam clamp at $30^{\circ} \mathrm{C}$. The soak time was 5 minutes (at $28^{\circ} \mathrm{C}$ ) and the ramp rate was $3^{\circ} \mathrm{C} / \mathrm{min}$. The frequency was $1 \mathrm{~Hz}$ and the amplitude was $15 \mu \mathrm{m}$. Test sample dimensions were $65 \mathrm{~mm} \times 12.9 \mathrm{~mm} \times 3.3 \mathrm{~mm}$ (supported length $41.6 \mathrm{~mm}$ ).

2.2.7. Izod Impact Test. Izod impact test (notched) was conducted by using an izod impact tester (Tinius Olsen, Model Impact 104, PA, USA) according to ASTM D 256: standard test method for determining the izod pendulum impact resistance of plastics. No additional load was added to the pendulum. Test sample dimensions were $63.5 \mathrm{~mm} \times$ $12.9 \mathrm{~mm} \times 3.3 \mathrm{~mm}$ with a $2 \mathrm{~mm}$ notch being made in the middle of the sample.

2.2.8. Melt Flow Index (MFI). Melt flow index was measured by using an extrusion plastometer (Tinius Olsen, Model MP 600, PA, USA) according to ASTM D 1238: standard test method for melt flow rates of thermoplastics by extrusion plastometer. The applied temperature and load were $190^{\circ} \mathrm{C}$ and $2.16 \mathrm{Kg}$, respectively.

2.2.9. Scanning Electron Microscopy (SEM). SEM test samples were obtained from the fracture surfaces of tensile specimens. These fracture surfaces were covered with a conductive gold-palladium layer by using a Balzers SCD 030 sputter coater (BAL-TEC RMC, Tucson, AZ, USA). Coated samples were then tested by using a JEOL JSM-6490LV scanning electron microscope (JEOL USA, Peabody, MA, USA). The accelerating voltage was $15 \mathrm{KeV}$.

2.2.10. Fiber Length Measurement. Wood fiber length of composites was measured by dissolving the polymer in acetone at $130^{\circ} \mathrm{C}$, with constant stirring for two hours. After the polymer dissolved, the wood fibers settled at the bottom of the container. Wood fibers were then separated from the solution and dried in an oven at $105^{\circ} \mathrm{C}$ for $12 \mathrm{~h}$. A Zeiss microscope (Axiovart 40 Mat) was used to evaluate 100 fiber lengths.

2.2.11. Differential Scanning Calorimetry (DSC). DSC was performed by using a TA instrument (DSC, Q1000, DE, USA) from $-10^{\circ} \mathrm{C}$ to $240^{\circ} \mathrm{C}$ with a nitrogen flow rate of $50 \mathrm{ml} / \mathrm{min}$. The heating or ramp rate was $10^{\circ} \mathrm{C} / \mathrm{min}$. Each sample weighed approximately $10 \mathrm{mg}$.

2.2.12. Thermogravimetric Analysis (TGA). TGA was accomplished by using a TA instrument (TGA, Q500, DE, USA) using temperature range from $25^{\circ} \mathrm{C}$ to $800^{\circ} \mathrm{C}$ in air as a sample gas (flow rate $60 \mathrm{ml} / \mathrm{min}$ ) and nitrogen as a balance gas (flow rate $40 \mathrm{ml} / \mathrm{min}$ ). The heating rate was controlled at $10^{\circ} \mathrm{C} / \mathrm{min}$. Each sample weighed approximately $10 \mathrm{mg}$.

2.2.13. Fourier Transform Infrared Spectroscopy (FTIR). A Thermo Scientific Nicolet 8700 spectrometer was used to perform FTIR. The test was done in photoacoustic mode and in the range of $700-3500 \mathrm{~cm}^{-1}$. All the samples had an approximate thickness of $0.5 \mathrm{~mm}$. FTIR data analysis was done by using OMNIC spectra software.

2.2.14. Gel Permeation Chromatography (GPC). The acetone solution containing dissolved PLA produced in Section 2.2.10 was used for GPC. The acetone solution containing PLA was exposed in the open air at room temperature $\left(25^{\circ} \mathrm{C}\right)$ to obtain dried PLA. Dried PLA was then dissolved in tetrahydrofuran (THF) to make another solution (concentration $2 \mathrm{mg} / \mathrm{ml}$ ). This solution was used in a GPC apparatus (EcoSEC HLC8320GPC, Tosoh Bioscience, Japan) with an injection volume of $20 \mu \mathrm{l}\left(\right.$ at $40^{\circ} \mathrm{C}$ ) and an eluent (THF) flow rate of $0.4 \mathrm{ml} / \mathrm{min}$. Two columns (TSKgel SuperHM-L $6.00 \mathrm{~mm} \mathrm{ID} \times 15 \mathrm{~cm}$ ) and a differential refractometer detector (DRI) were also used with the GPC apparatus, to measure the molecular weight of PLA.

2.2.15. Statistical Analysis. Statistical analysis was conducted on the data of mechanical and thermomechanical tests with a confidence level of $95 \%$ by using Minitab 17 (Minitab, PA, USA). The mean comparison of different samples was conducted using Tukey's test. Means with different alphabet show significant difference in the properties. Eight replicates from each cycle were tested for all the mechanical properties and five replicates for melt flow index.

\section{Discussion}

3.1. Effect of Wood Flour Content on Virgin Composites. Higher WF content ( $50 \mathrm{wt} \%$ filler) increased stiffness properties and tensile and flexural modulus but showed no impact on the tensile and flexural strength. On the contrary, higher filler content decreased composite strain properties. No improvement in the strength properties of composites despite higher filler content can be attributed to poor interfacial adhesion between the fiber and polymer matrix. It is possible that higher filler content could produce fiber agglomeration 


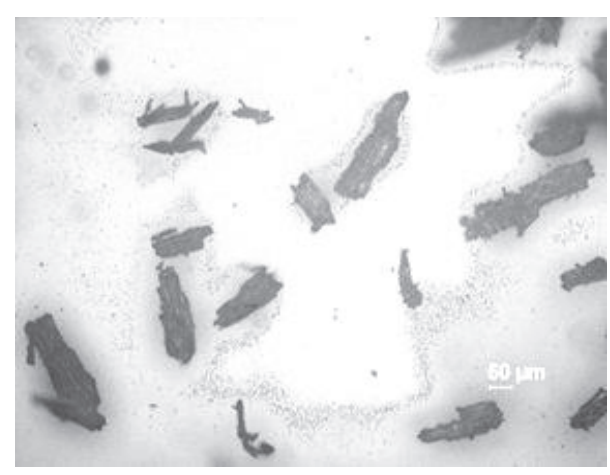

(a)

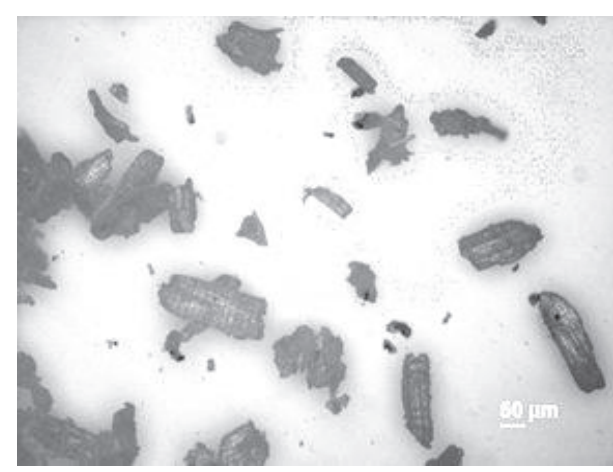

(b)

Figure 1: Fibers of WF 30 PLA composite at (a) cycle 0 and (b) cycle 6 (magnification 10x).

in the composite matrix resulting in stress concentration, as stress concentration initiates crack propagation which leads to lower composite strength properties [13].

Higher filler composite showed increased tensile, flexural, and storage modulus by $950 \mathrm{MPa}, 450 \mathrm{MPa}$, and $450 \mathrm{MPa}$, respectively, as compared to lower filler (30 wt $\%$ filler) composite. This is because the stiffness properties of biocomposites mainly depend on wood flour content [7, 14]. In higher filler composite, higher constrain to polymer chain movement is created, and hence the composite stiffness is increased $[2,9,14]$. As the composite becomes stiffer, it produces more resistance to mechanical or thermal stresses and thus showed a decrease in strain properties.

Similarly, heat deflection temperature (HDT) properties showed no response to WF loading levels. This is because lower crystalline polymers, such as PLA, show HDT nearly close to their glass transition temperature, while higher crystalline polymers show HDT around their melting temperature [18]. Higher filler content did not play any role in altering the HDT of lower crystalline polymers [23, 24].

3.2. Effect of Recycling on Fiber Length. The fiber length in WF 30 PLA and WF 50 PLA composites decreased with successive reprocessing. At cycle 0 and cycle 6, the average fiber lengths were, respectively, $253.24 \mu \mathrm{m}$ and $111.15 \mu \mathrm{m}$, which are noticeably lower than the fiber length of original wood flour (Table 1 and Figure 1). This could be due to two probable reasons, lower MFI of PLA ( $6 \mathrm{~g} / 10 \mathrm{~min})$ and higher screw $\mathrm{rpm}$ of the extruder $(200 \mathrm{rev} / \mathrm{min})$, both of which can lead to higher shear stress during extrusion which can result in high attrition causing lower average fiber length in the PLA composite. The results are in agreement with previously reported results $[1,22]$. Figure 2 shows the normal distribution of fiber lengths of the composite at cycle 0 and cycle 6.

3.3. Effect of Recycling on Molecular Weight of PLA. Table 2 shows the average molecular weights of WF 30 PLA composite at cycle 0 and cycle 6 . Both types of molecular weights, weight averaged $\left(M_{w}\right)$ and number averaged $\left(M_{n}\right)$, showed a decrease with successive recycling. These results agree with the work of other researchers [25]. The polydispersity index (PDI) showed an increase with increased number

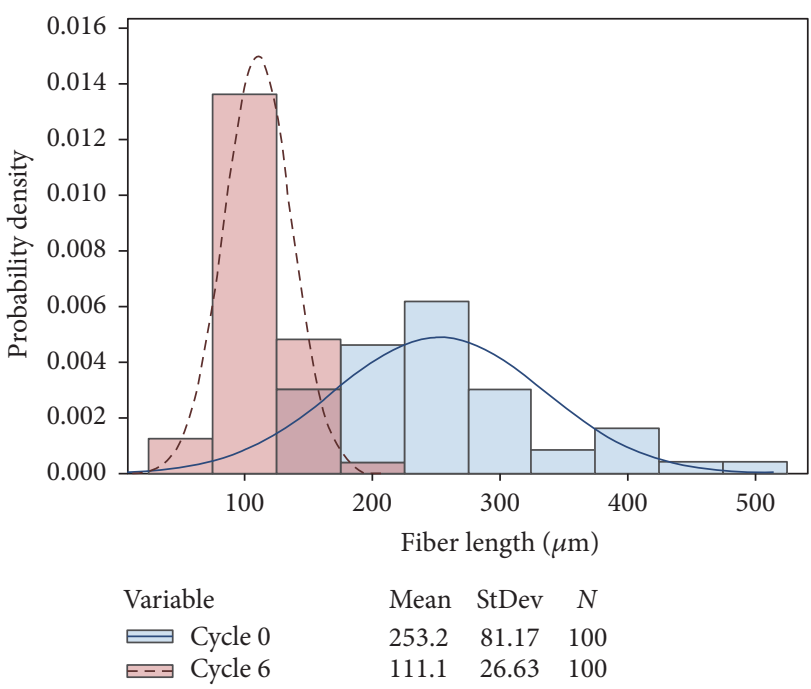

FIGURE 2: Normal distribution plot of fiber length of WF 30 PLA composite at cycle 0 and cycle 6 .

TABLE 2: Fiber length and molecular weight of WF 30 PLA composite at cycle 0 and cycle 6 .

\begin{tabular}{lcc}
\hline Property & Cycle 0 & Cycle 6 \\
\hline Average fiber length $(\mu \mathrm{m})$ & 253.24 & 111.15 \\
$M_{w}(\mathrm{~g} / \mathrm{mole})$ & 151,115 & 81,958 \\
$M_{n}(\mathrm{~g} / \mathrm{mole})$ & 133,762 & 50,742 \\
Polydispersity index $(\mathrm{PDI})$ & 1.13 & 1.62 \\
\hline
\end{tabular}

of reprocessing cycles. This increase in PDI also implies a decrease in molecular weights of PLA [26]. This could be attributed to the breakage of polymer chains due to thermal degradation. Recycling of polymer leads to decrease in $M_{n}$ resulting in higher PDI.

3.4. Effect of Recycling on Composite Strength Properties. Strength properties of WF 30 PLA composite (tensile strength, flexural strength, and impact strength) decreased sharply at cycle 6 , while they did not exhibit any shift in the previous cycles (Table 3 ). Strength properties of biocomposites primarily depend on fiber length (or aspect 


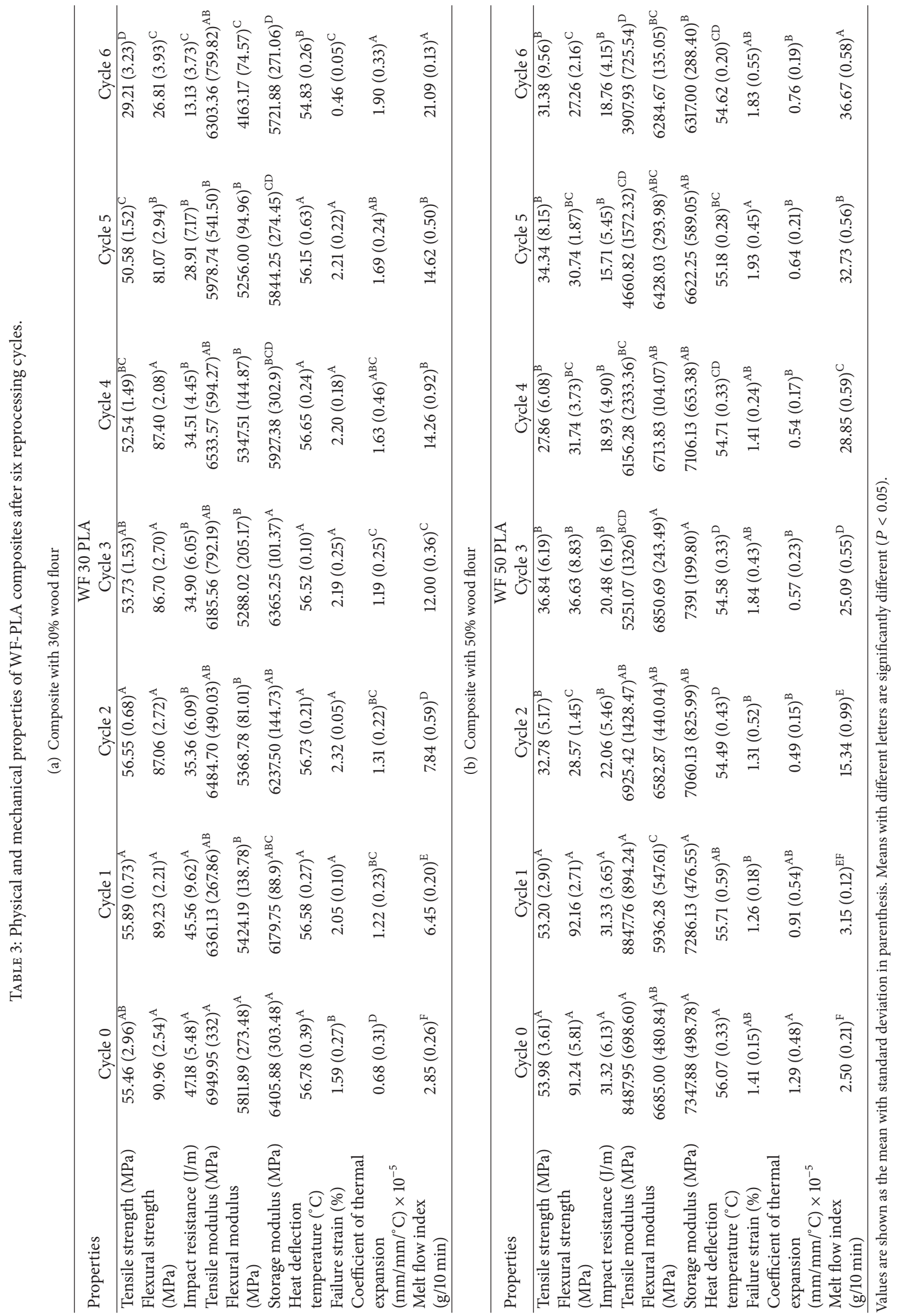




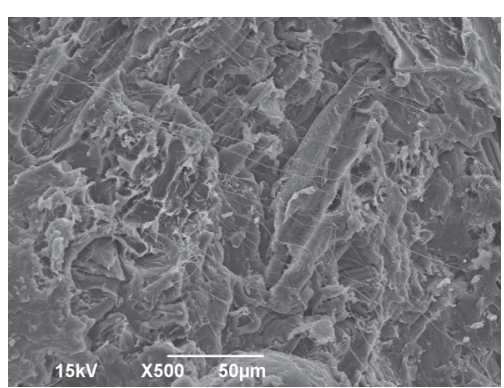

(a)

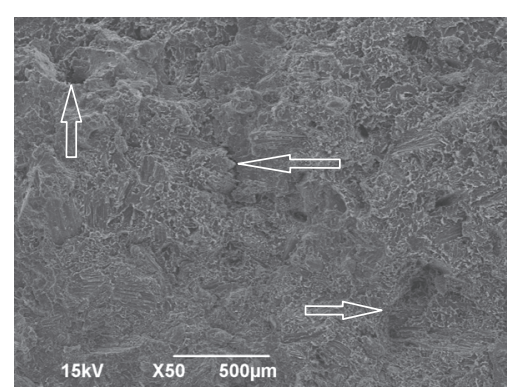

(b)

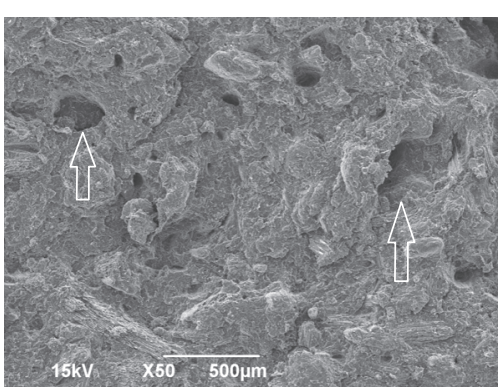

(c)

FIgURe 3: SEM of WF-PLA composite at (a) cycle 0 (WF 30 PLA), (b) cycle 6 (WF 30 PLA), and (c) cycle 2 (WF 50 PLA).

TABLE 4: Relative difference in means of properties of WF/PLA composites between cycle 0 and cycle 6.

\begin{tabular}{lcc}
\hline Properties & WF 30 PLA composite (\%) & WF 50 PLA composite (\%) \\
\hline Tensile strength $(\mathrm{MPa})$ & -47.34 & -41.86 \\
Tensile modulus $(\mathrm{MPa})$ & -9.30 & -53.96 \\
Failure strain $(\%)$ & -71.22 & 29.20 \\
Flexural strength $(\mathrm{MPa})$ & -70.53 & -70.12 \\
Flexural modulus $(\mathrm{MPa})$ & -28.37 & -5.99 \\
Impact resistance $(\mathrm{J} / \mathrm{m})$ & -72.18 & -40.10 \\
Heat deflection temperature $\left({ }^{\circ} \mathrm{C}\right)$ & -3.43 & -2.58 \\
Storage modulus $(\mathrm{MPa})$ & -10.68 & -14.03 \\
Coefficient of thermal expansion $\left(\mathrm{mm} / \mathrm{mm} /{ }^{\circ} \mathrm{C}\right)$ & 175.94 & -40.93 \\
Melt flow index $(\mathrm{g} / 10 \mathrm{~min})$ & 640.37 & 1364.60 \\
\hline
\end{tabular}

Negative sign shows a decrease and a positive one shows an increase in the value of the property.

ratio), fiber content, void content, interfacial adhesion, and molecular weight of polymer. In this case, fiber length and molecular weight of polymer possibly decreased by a greater extent at cycle 6 than the previous cycles. In addition, crack propagation and fiber pull-outs are observed at cycle 6 that indicate lower interfacial adhesion between the fiber and matrix (Figures 3(a) and 3(b)). This lower interfacial adhesion, attributable to repeated heat and shear stress history due to extrusion, probably results in lower strength properties of the composite [1].

On the contrary, strength properties of WF 50 PLA composite decreased vastly after cycle 2 and then became somewhat constant up to cycle 6 (Tables 3(a) and 3(b)). This could be due to the higher degradation in fiber and polymer, coupled with lower interfacial adhesion due to higher filler content at cycle 2. Microvoids were also observed in the composite matrix at cycle 2 (Figure 3 ) that could significantly contribute towards lower strength properties. Strength properties of composites were almost constant from cycle 2 to cycle 6 , as the number of pores at cycle 2 and cycle 6 remained equivalent.

The sudden change in strength properties for WF 50 PLA at cycle 2 can be related to higher amount of shear stress during extrusion as well as inherent moisture content due to higher amount of wood flour. It is reported that PLA is highly sensitive to shear stress and moisture, which can lead to a rapid decrease in strength properties in highly filled composites [1].
3.5. Effect of Recycling on Composite Stiffness Properties. Composite stiffness properties experimented in this study include tensile modulus, flexural modulus, storage modulus, and heat deflection temperature (HDT). All these properties showed a gradual decrease with increasing number of reprocessing cycles for both composites (Tables 3(a) and 3(b)). This may be due to the less efficient stress transfer from the matrix to fiber, that is, caused by (1) fiber and polymer degradation, (2) increased number of microvoids, (3) less polymer chain entanglement by fibers, and (4) poor fiber-matrix interfacial adhesion with successive recycling $[22,27]$.

Overall, most stiffness properties showed minor decrease, from cycle 0 to cycle 6 for both formulations of composites, as compared to the corresponding strength properties (Tables $3(a)$ and 3(b)). For example, after reprocessing six times, flexural modulus for higher and lower filler composite decreased by $6 \%$ and $28 \%$, respectively, while both flexural strengths decreased approximately $70 \%$ (Table 4 ). As mentioned earlier (Section 3.1), fiber content is the most important parameter to determine stiffness properties of biocomposites [7, 14]. Since the fiber content was constant for each formulation during reprocessing, the amount of polymer chain entanglement decreased less, which contributed to decrease in composite stiffness properties. These findings are consistent with the findings of other research workers $[1,22]$.

The tensile modulus of WF 50 PLA composites from cycle 0 and cycle 6 showed a much higher decrease (54\%) than the corresponding flexural modulus (6\%) (Tables 3(a) and 3(b)). 


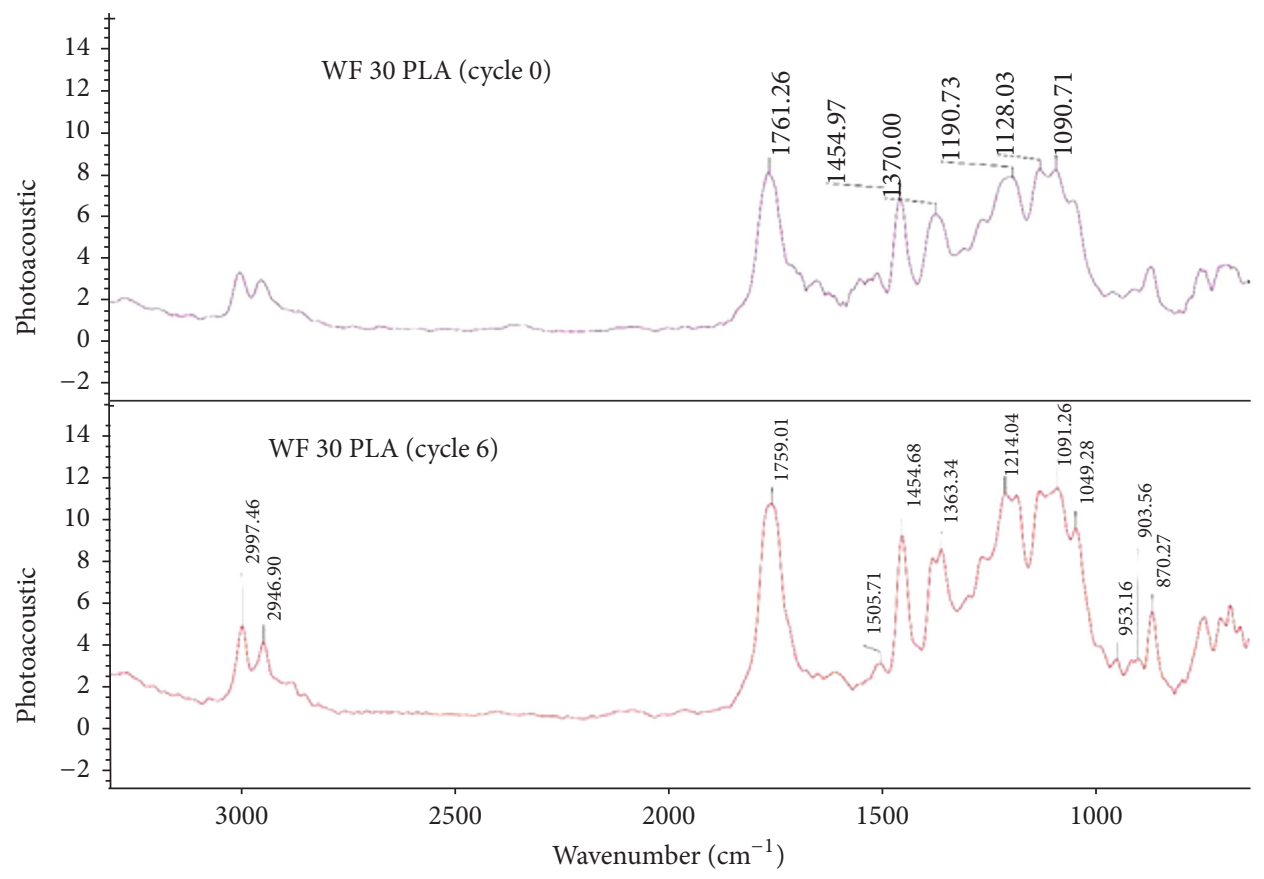

FIgURE 4: FTIR spectra of WF 30 PLA composite at cycle 0 and cycle 6.

TABLE 5: FTIR functional group analysis of WF 30 PLA composite at cycle 0 and cycle 6 [20, 21].

\begin{tabular}{lcc}
\hline Characteristic absorption $\left(\mathrm{cm}^{-1}\right)$ & Functional group & Indication by functional group \\
\hline 1769 & Carboxylic acid & Oxidation \\
1505 & Carboxylic acid & Oxidation \\
1454 & Amine & Weaker bond \\
1370 & Alcohols or phenols & Oxidation \\
1214 & Ether/amine & Oxidation/weaker bond \\
1091 & Ether/amine & Oxidation/weaker bond \\
1049 & Ether/amine & Oxidation/weaker bond \\
870 & Amine & Weaker bond \\
\hline
\end{tabular}

The difference in the property values could be due to the difference in testing methods since tensile test is thickness dependent and flexural test is surface property dependent [19].

3.6. Effect of Recycling on Composite Strain Properties. The impact of reprocessing was investigated on the thermomechanical strain properties of composites such as failure strain, coefficient of thermal expansion (CTE), and melt flow index (MFI). For both composites, most of these strain properties showed an increase with repetitive extrusion cycles (Tables 3(a) and 3(b)). This increase in composite strain is caused by the same factors (or change in factors) that have reduced composite stiffness with successive recycling (Section 3.5).

However, for WF 30 PLA composite, although CTE increased with consecutive recycling, failure strain first increased from cycle 0 to cycle 5 but then sharply decreased at cycle 6 (Table 3(a)). This could be attributed to the fact that failure strain was measured with a tensile load while
CTE was measured with no preload force and is temperature dependent. At cycle 6, the composite may have degraded to the extent that it could not withstand higher load (Table 3(a)) and failed earlier as compared to the previous cycles. As the composite failed earlier, its failure strain decreased instead of increasing. In contrast, CTE showed a higher value at cycle 6 due to the absence of external force that resulted in no failure of the composite.

3.7. FTIR Analysis. Figure 4 and Table 5, respectively, show the FTIR spectra and FTIR analysis conducted on WF 30 PLA composite at cycle 0 and cycle 6 . This analysis reveals the formation of different functional groups during extrusion that implies composite degradation caused by oxidation and weaker bond formation. Both composites show almost the same characteristic absorptions at cycle 0 and cycle 6 . However, because of unequal thickness and heterogeneity of small samples, the relative degradation at cycle 6 as compared to cycle 0 could not be measured. 


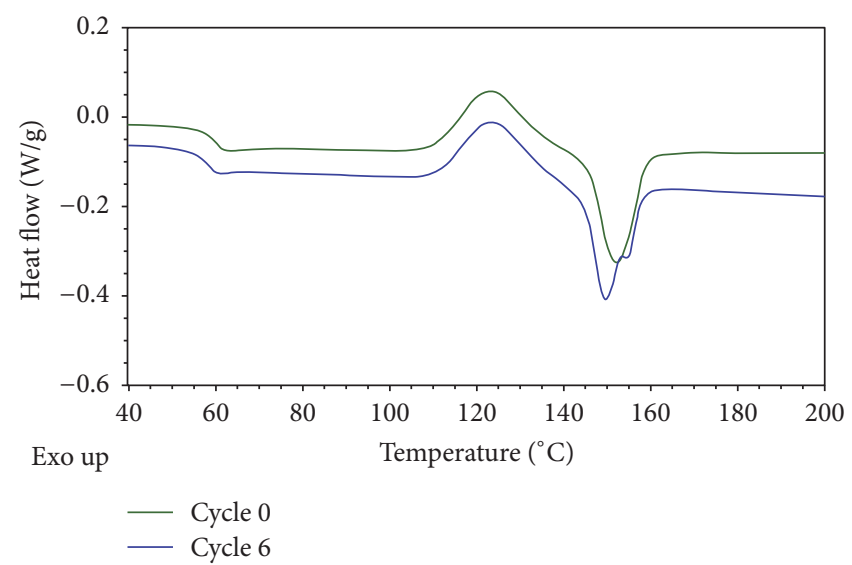

FIgURE 5: DSC analysis curves of WF 50 PLA composite at cycle 0 and cycle 6.

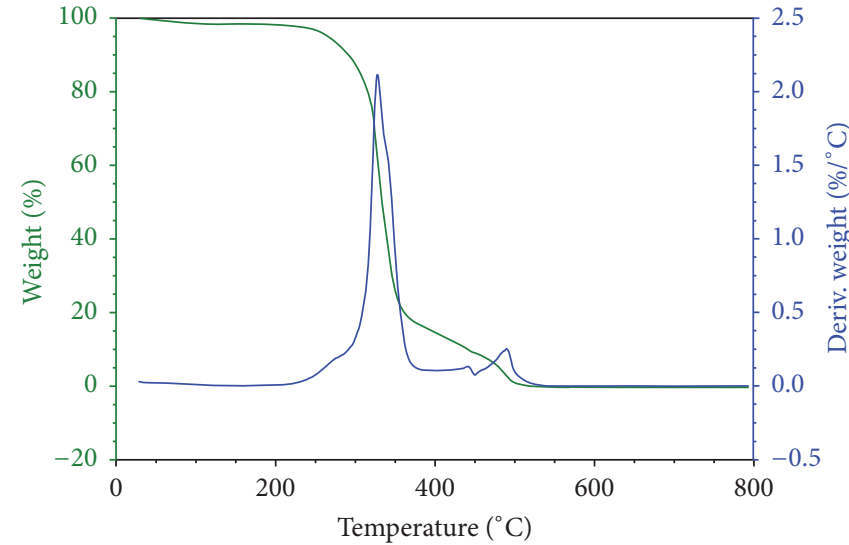

(a)

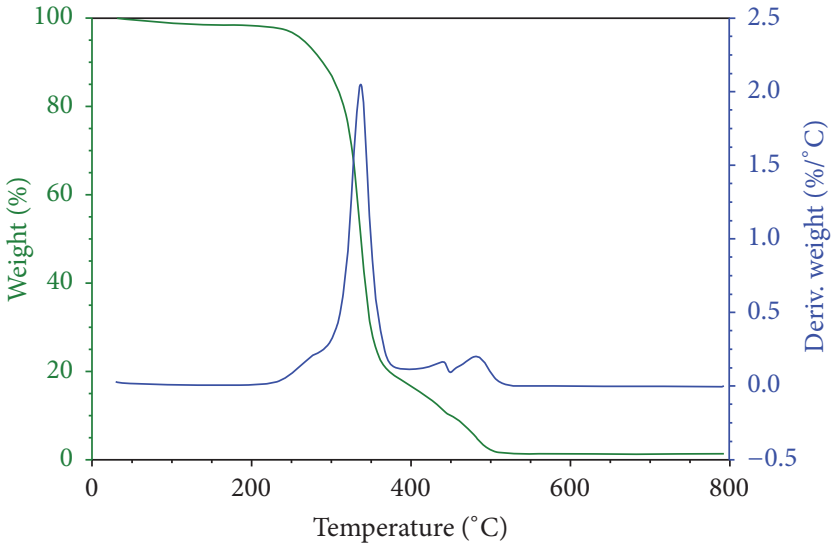

(b)

Figure 6: TGA curve and its 1st derivative of WF 50 PLA composite at (a) cycle 0 and (b) cycle 6.

3.8. Effect of Recycling on Crystallinity and Thermal Stability. The percentage crystallinity of PLA in the WF 50 PLA composites was measured at cycle 0 and cycle 6 by the following equation [2]:

$$
\% \text { Crystallinity }=\left(\frac{\Delta H_{\text {exp }}}{\Delta H}\right) \times\left(\frac{1}{W}\right) \times 100 \text {. }
$$

Here, $\Delta H_{\text {exp }}$ is the experimental heat of fusion provided by DSC, $\Delta H$ is the heat of fusion of pure PLA $(93.1 \mathrm{~J} / \mathrm{g})$, and $W$ is the mass fraction of PLA in the composite. The crystallinity of PLA in composite decreased with increased number of reprocessing cycles (Figure 5 and Table 6). This is because the fibers probably degraded at a relatively higher amount that PLA, at cycle 6 . From cycle 0 to cycle 6 , the average fiber length decreased approximately 56\%, while the weight averaged molecular weight of PLA decreased $45.7 \%$ (Table 2). Similarly, the melting temperature of PLA, at cycle 6 , decreased with successive reprocessing due to the molecular weight reduction of PLA [22].

However, thermal stability of WF 50 PLA composite increased with consecutive recycling (Table 7 and Figure 6)
TABLE 6: DSC analysis of WF 50 PLA composite at cycle 0 and cycle 6.

\begin{tabular}{lcc}
\hline Properties & Cycle 0 & Cycle 6 \\
\hline Melting point $\left({ }^{\circ} \mathrm{C}\right)$ & 152.15 & 149.64 \\
Crystallization temperature $\left({ }^{\circ} \mathrm{C}\right)$ & 145.33 & 144.24 \\
Heat of fusion $(\mathrm{J} / \mathrm{g})$ & 16.64 & 15.42 \\
Crystallinity $(\%)$ & 38.03 & 35.24 \\
\hline
\end{tabular}

TABLE 7: TGA of WF 50 PLA composite at cycle 0 and cycle 6.

\begin{tabular}{lcc}
\hline Property & Cycle 0 & Cycle 6 \\
\hline Onset thermal degradation Temperature $\left({ }^{\circ} \mathrm{C}\right)$ & 312.42 & 316.10 \\
Fastest decomposition Temperature $\left({ }^{\circ} \mathrm{C}\right)$ & 327.06 & 337.22 \\
Residue $(\%)$ & 0 & 1.35 \\
\hline
\end{tabular}

that was caused by the polymer degradation (molecular weight reduction) at cycle 6 [22]. Lower number of volatiles at cycle 6 could be a probable reason for increased thermal stability of the composites. 


\section{Summary}

Two wood flour/PLA composites were formulated by extrusion, each of which contains 30 or 50 wt $\%$ filler, 3 wt $\%$ PLAg-MA, and the rest amount of PLA. Both composites were separately reprocessed six times by extrusion. Samples for mechanical and thermomechanical tests were prepared by injection molding. Both 30 and $50 \mathrm{wt} \%$ filler composites showed a sharp decrease in tensile strength, flexural strength, and impact resistance at cycle 6 and cycle 2, respectively. Both composites also showed a decrease in tensile modulus, flexural modulus, and storage modulus with successive recycling, while they exhibited an increase in failure strain, coefficient of thermal expansion, and melt flow index. With consecutive reprocessing, composite thermal stability increased, while polymer crystallinity decreased. To sum up, composite strength and stiffness properties decreased, but strain properties increased with successive recycling due to the fiber length reduction and PLA degradation.

\section{Conflicts of Interest}

The authors declare that there are no conflicts of interest regarding the publication of this paper.

\section{Acknowledgments}

The authors gratefully acknowledge the financial support from National Science Foundation North Dakota EPSCoR for conducting this research.

\section{References}

[1] A. Le Duigou, I. Pillin, A. Bourmaud, P. Davies, and C. Baley, "Effect of recycling on mechanical behaviour of biocompostable flax/poly(l-lactide) composites," Composites Part A: Applied Science and Manufacturing, vol. 39, no. 9, pp. 1471-1478, 2008.

[2] S. Pilla, S. Gong, E. O'Neill, L. Yang, and R. M. Rowell, "Polylactide-recycled wood fiber composites," Journal of Applied Polymer Science, vol. 111, no. 1, pp. 37-47, 2009.

[3] R. Salehiyan, A. A. Yussuf, N. F. Hanani, A. Hassan, and A. Akbari, "Polylactic acid/polycaprolactone nanocomposite: Influence of montmorillonite and impact modifier on mechanical, thermal, and morphological properties," Journal of Elastomers and Plastics, vol. 47, no. 1, pp. 69-87, 2015.

[4] E. Petinakis, L. Yu, G. Edward, K. Dean, H. Liu, and A. D. Scully, "Effect of matrix-particle interfacial adhesion on the mechanical properties of poly(lactic acid)/wood-flour microcomposites," Journal of Polymers and the Environment, vol. 17, no. 2, pp. 83-94, 2009.

[5] T. Qiang, D. Yu, and H. Gao, "Wood flour/polylactide biocomposites toughened with polyhydroxyalkanoates," Journal of Applied Polymer Science, vol. 124, no. 3, pp. 1831-1839, 2012.

[6] L. Yao, Y. Wang, Y. Li, and J. Duan, "Thermal properties and crystallization behaviors of polylactide/redwood flour or bamboo fiber composites," Iranian Polymer Journal, vol. 26, no. 2, pp. 161-168, 2017.

[7] H. Anuar, A. Zuraida, J. G. Kovacs, and T. Tabi, "Improvement of mechanical properties of injection-molded polylactic acidkenaf fiber biocomposite," Journal of Thermoplastic Composite Materials, vol. 25, no. 2, pp. 153-164, 2012.
[8] H. Salmah, S. C. Koay, and O. Hakimah, "Surface modification of coconut shell powder filled polylactic acid biocomposites," Journal of Thermoplastic Composite Materials, vol. 26, no. 6, pp. 809-819, 2013.

[9] K. S. Chun, S. Husseinsyah, and H. Osman, "Mechanical and thermal properties of coconut shell powder filled polylactic acid biocomposites: effects of the filler content and silane coupling agent," Journal of Polymer Research, vol. 19, no. 5, article 9859, 2012.

[10] K.-W. Kim, B.-H. Lee, H.-J. Kim, K. Sriroth, and J. R. Dorgan, "Thermal and mechanical properties of cassava and pineapple flours-filled PLA bio-composites," Journal of Thermal Analysis and Calorimetry, vol. 108, no. 3, pp. 1131-1139, 2012.

[11] K. Hamad, M. Kaseem, H. W. Yang, F. Deri, and Y. G. Ko, "Properties and medical applications of polylactic acid: a review," Express Polymer Letters, vol. 9, no. 5, pp. 435-455, 2015.

[12] G. Faludi, G. Dora, K. Renner, J. Móczó, and B. Pukánszky, "Biocomposite from polylactic acid and lignocellulosic fibers: structure-property correlations," Carbohydrate Polymers, vol. 92, no. 2, pp. 1767-1775, 2013.

[13] M. Morreale, R. Scaffaro, A. Maio, and F. P. La Mantia, "Effect of adding wood flour to the physical properties of a biodegradable polymer," Composites Part A: Applied Science and Manufacturing, vol. 39, no. 3, pp. 503-513, 2008.

[14] A. K. Bledzki, A. Jaszkiewicz, and D. Scherzer, "Mechanical properties of PLA composites with man-made cellulose and abaca fibres," Composites Part A: Applied Science and Manufacturing, vol. 40, no. 4, pp. 404-412, 2009.

[15] M. S. Huda, L. T. Drzal, M. Misra, A. K. Mohanty, K. Williams, and D. F. Mielewski, "A study on biocomposites from recycled newspaper fiber and poly(lactic acid)," Industrial and Engineering Chemistry Research, vol. 44, no. 15, pp. 5593-5601, 2005.

[16] M. Hrabalova, A. Gregorova, R. Wimmer, V. Sedlarik, M. Machovsky, and N. Mundigler, "Effect of wood flour loading and thermal annealing on viscoelastic properties of poly(lactic acid) composite films," Journal of Applied Polymer Science, vol. 118, no. 3, pp. 1534-1540, 2010.

[17] P. Dhar, D. Tarafder, A. Kumar, and V. Katiyar, "Thermally recyclable polylactic acid/cellulose nanocrystal films through reactive extrusion process," Polymer (United Kingdom), vol. 87, pp. 268-282, 2016.

[18] C. Nyambo, A. K. Mohanty, and M. Misra, "Polylactide-based renewable green composites from agricultural residues and their hybrids," Biomacromolecules, vol. 11, no. 6, pp. 1654-1660, 2010.

[19] M. S. Huda, A. K. Mohanty, L. T. Drzal, E. Schut, and M. Misra, “"'green" composites from recycled cellulose and poly(lactic acid): Physico-mechanical and morphological properties evaluation," Journal of Materials Science, vol. 40, no. 16, pp. 42214229, 2005.

[20] “Table of ir absorptions,” 2016, http://www.Chem.Ucla.Edu/ webspectra/irtable.html.

[21] "Infrared spectroscopy," 2016, https://www2.Chemistry.Msu .Edu/faculty/reusch/virttxtjml/spectrpy/infrared/infrared.htm.

[22] M. D. H. Beg and K. L. Pickering, "Reprocessing of wood fibre reinforced polypropylene composites. Part I: Effects on physical and mechanical properties," Composites Part A: Applied Science and Manufacturing, vol. 39, no. 7, pp. 1091-1100, 2008.

[23] V. Nagarajan, K. Zhang, M. Misra, and A. K. Mohanty, "Overcoming the fundamental challenges in improving the impact strength and crystallinity of PLA biocomposites: Influence of 
nucleating agent and mold temperature," ACS Applied Materials and Interfaces, vol. 7, no. 21, pp. 11203-11214, 2015.

[24] N. Graupner, "Improvement of the mechanical properties of biodegradable hemp fiber reinforced poly(lactic acid) (PLA) composites by the admixture of man-made cellulose fibers," Journal of Composite Materials, vol. 43, no. 6, pp. 689-702, 2009.

[25] I. Zembouai, S. Bruzaud, M. Kaci, A. Benhamida, Y.-M. Corre, and Y. Grohens, "Mechanical Recycling of Poly(3Hydroxybutyrate-co-3-Hydroxyvalerate)/Polylactide Based Blends," Journal of Polymers and the Environment, vol. 22, no. 4, pp. 449-459, 2014.

[26] N. Petchwattana, S. Covavisaruch, and J. Sanetuntikul, "Recycling of wood-plastic composites prepared from poly(vinyl chloride) and wood flour," Construction and Building Materials, vol. 28, no. 1, pp. 557-560, 2012.

[27] K. B. Adhikary, S. Pang, and M. P. Staiger, "Dimensional stability and mechanical behaviour of wood-plastic composites based on recycled and virgin high-density polyethylene (HDPE)," Composites Part B: Engineering, vol. 39, no. 5, pp. 807-815, 2008. 

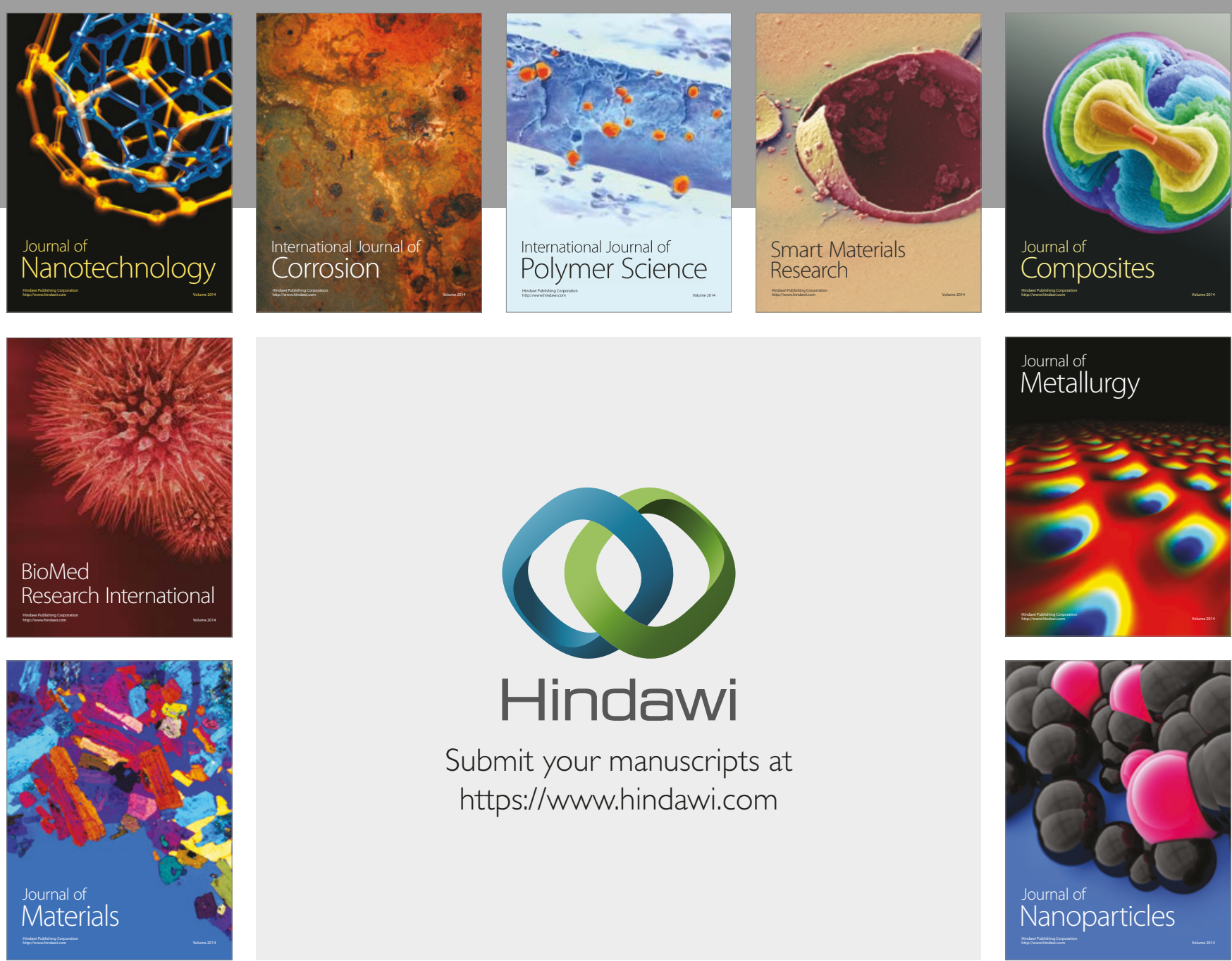

\section{Hindawi}

Submit your manuscripts at

https://www.hindawi.com
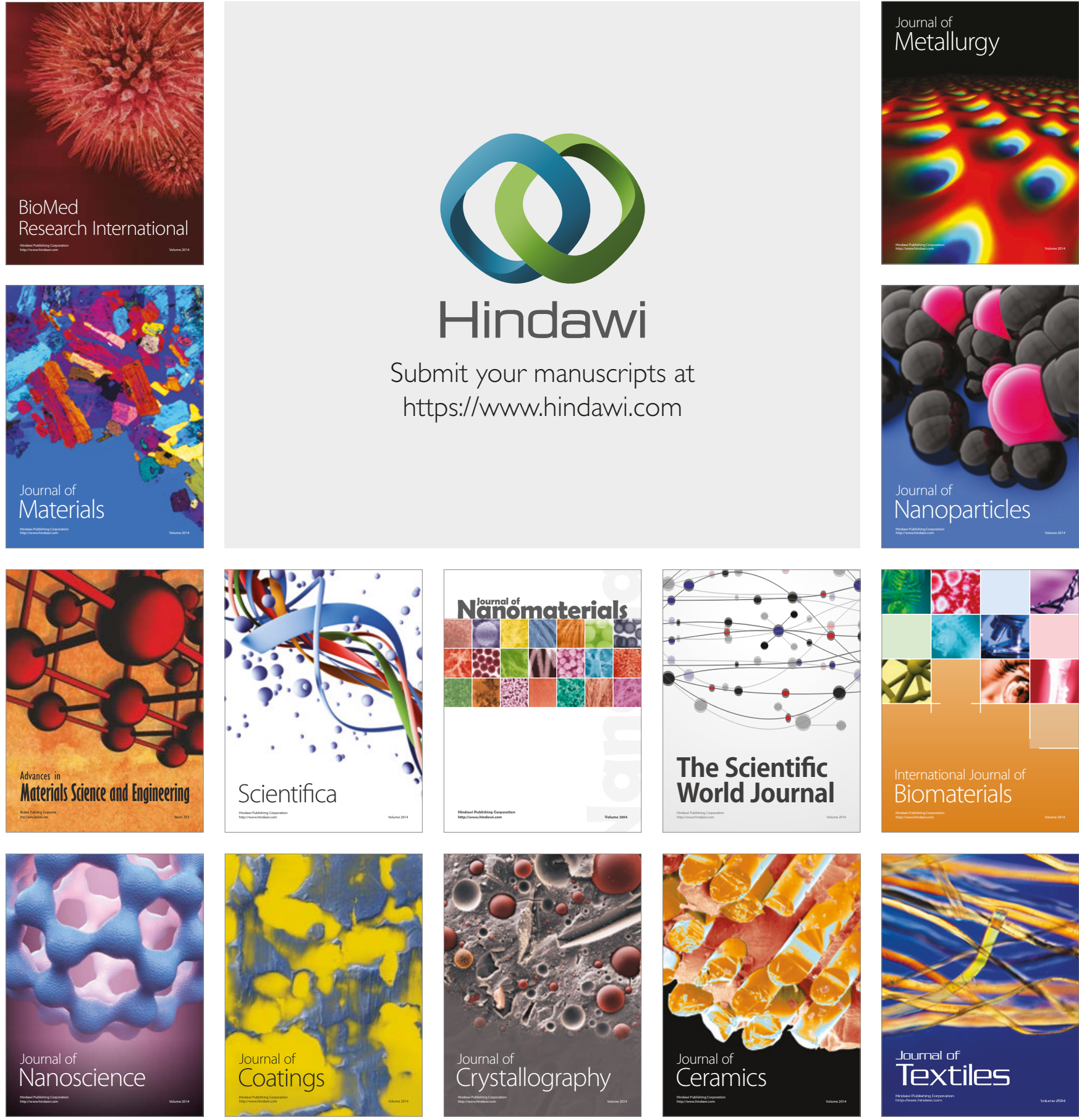

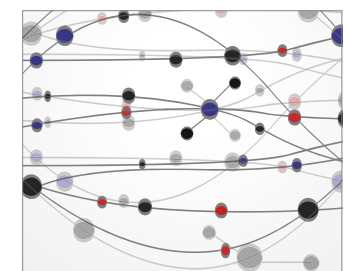

The Scientific World Journal
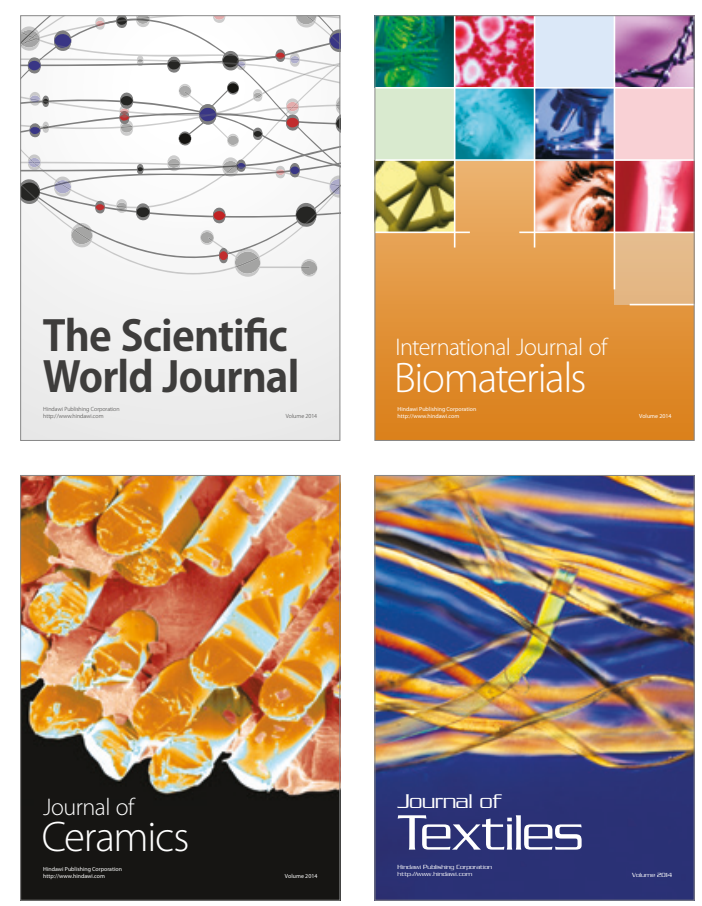